\title{
Plant gametogenesis: conservation and contrasts in development
}

\author{
Zoe A Wilson and Caiyun Yang \\ Plant Sciences Division, School of Biosciences, Sutton Bonington Campus, University of Nottingham, \\ Nottingham LE12 5RD, UK
}

Correspondence should be addressed to Z A Wilson; Email: Zoe.Wilson@nottingham.ac.uk

\begin{abstract}
Although the process of gamete formation in plants has many unique features, much has been learnt from the comparative analysis between plants and other eukaryotic systems. Plants have a number of factors that have made them desirable for the analysis of gamete development; these include late germline specification, the non-lethality of mutations affecting gamete development and the large size of their chromosomes. The availability of the fully annotated Arabidopsis genome and comparative analysis using yeast, animal and $E$. coli has led to the identification and functional characterisation of many genes with roles in gamete development, principally those associated with meiosis, recombination and DNA repair. The advantages that plants give with the use of mutant screens to identify genes associated with gamete formation have also provided access to genes that are difficult to characterise by alternative routes. This has yielded novel information regarding the processes of gamete formation in higher plants. The times may now be changing with the advantages that plants provide serving to advance knowledge of gamete formation in other eukaryotic systems.

Reproduction (2004) 128 483-492
\end{abstract}

\section{Introduction}

The process of gamete development in higher plants mirrors that seen in animals; however, although there is conservation of process and substantial information can be obtained by the comparative analysis of distantly related organisms, there remain distinct differences which are specific to the organisms concerned. These differences include germline specification; plants have the ability to produce gametes at a late developmental stage that has not been predetermined, whereas gamete formation in animals is confined to distinct regions that are established at an early embryonic stage. Also although fertility may be frequently compromised by the mutation of genes associated with gamete formation, with defects frequently resulting in reduced fertility, they are rarely lethal in plants. Such defects can often be maintained since most plants produce both male and female gametes and often the formation of one type of gamete remains unaffected by the mutation; plants are also able to reproduce asexually or via non-fertilising means, for example apomixes.

The initiation of meiosis is a key stage in the developmental process for higher plants since it provides the trigger for splitting the sporophytic and gametophytic generations. Although much is known about the process of meiosis, and many homologies have been detected between animals and plants, little is known about the plant signals that switch development from mitosis to meiosis. Male and female gamete production is similar in higher plants with many genes playing a role in the development of both types of gametes; however, the subsequent fate of the male and female meiotic product is distinct. In male gamete production, all four meiotic products, microspores (male spore that will give rise to the male gametophyte) develop to produce viable fully functional pollen grains (McCormick 2004, Scott et al. 2004). However, in the female, usually only one of the four megaspores (female spore that will give rise to the female gametophyte) will continue to develop, whilst the remaining meiotic products degenerate by a form of programmed cell death (Schneitz et al. 1998, Yadegari \& Drews 2004). Much of what is known about gamete formation in higher plants has been obtained from the study of the model dicotyledonous plant Arabidopsis thaliana (Meinke et al. 1998) (Fig. 2 and Table 1) and the monocotyledon maize.

\section{Gamete development}

The development of reproductive organs and their meiocytes occurs late in plant development, unlike animals in which primordial germ cell development occurs early during embryonic development (Wylie 1999, Zhao \& Garbers 2002). The formation of gametes in higher plants occurs within defined organs, the anther for the male 
Table 1 Arabidopsis genes with roles in gamete formation

\begin{tabular}{|c|c|c|c|}
\hline Genes & Function & Orthologues & References \\
\hline$S P L / N Z Z$ & $\begin{array}{l}\text { MADS box transcription factor. } \\
\text { Sporogenesis initiation in male } \\
\text { and female organs }\end{array}$ & & $\begin{array}{l}\text { (Schiefthaler et al. 1999, } \\
\text { Yang et al. 1999b) }\end{array}$ \\
\hline EXS/EMS1 & $\begin{array}{l}\text { Altered numbers of male } \\
\text { archesporial initials, tapetum } \\
\text { and middle cell layer formation }\end{array}$ & $\begin{array}{l}\text { MAC1 (maize) } \\
M S P 1 \text { (rice) }\end{array}$ & $\begin{array}{l}\text { (Canales et al. 2002, } \\
\text { Zhao et al. 2002) }\end{array}$ \\
\hline GNE1 & $\begin{array}{l}\text { Tapetum and middle cell } \\
\text { layer formation }\end{array}$ & & (Sorensen et al. 2002) \\
\hline TPD1 & $\begin{array}{l}\text { In mutant tapetal cells } \\
\text { replaced with sporogenous cells }\end{array}$ & & (Yang et al. 2003b) \\
\hline SWI1/DYAD & $\begin{array}{l}\text { Involved in initiation } \\
\text { of chromosome cohesion }\end{array}$ & & (Siddiqi et al. 2000) \\
\hline SAP & $\begin{array}{l}\text { Transcription regulator involved } \\
\text { in completion of megasporocytes } \\
\text { meiosis and floral/organ number. }\end{array}$ & & (Byzova et al. 1999) \\
\hline DIF1/SYN1 & $\begin{array}{l}\text { Role in chromosome condensation. } \\
\text { Cohesin activity }\end{array}$ & REC8/RAD21 (yeast) & (Bai et al. 1999, Bhatt et al. 1999) \\
\hline$S D S$ & $\begin{array}{l}\text { Homologue synapsis, recombination } \\
\text { and bivalent formation. } \\
\text { Homology to cyclins }\end{array}$ & Cyclins & (Azumi et al. 2002) \\
\hline DSY1 & Synapsis & & (Ross et al. 1997) \\
\hline MEI1 & Role in male meiosis & $\begin{array}{l}\text { Human acrosin-trypsin } \\
\text { inhibitor }\end{array}$ & (He \& Mascarenhas 1998) \\
\hline AtDMC1 & $\begin{array}{l}\text { Chromsome partitioning. } \\
\text { RECA homologue }\end{array}$ & $D M C$ (yeast) & $\begin{array}{l}\text { (Klimyuk \& Jones 1997, } \\
\text { Couteau et al. 1999) }\end{array}$ \\
\hline ASY1 & $\begin{array}{l}\text { Male and female synapsis. } \\
\text { Associates with chromatin }\end{array}$ & HOP1 & $\begin{array}{l}\text { (Caryl et al. 2000, } \\
\text { Armstrong et al. 2002) }\end{array}$ \\
\hline RAD50 & $\begin{array}{l}\text { Double-strand break repair } \\
\text { and telomere maintenance }\end{array}$ & & $\begin{array}{l}\text { (Gallego et al. 2001, } \\
\text { Gallego \& White 2001) }\end{array}$ \\
\hline MRE11 & Double-strand break repair & & (Puizina et al. 2004) \\
\hline Rad-51-like & Recombination and damage repair & RAD51-like (yeast) & (Bleuyard \& White 2004) \\
\hline BRCA2 & $\begin{array}{l}\text { Role in homologous recombination } \\
\text { and meiotic progression, } \\
\text { BRCA2 associates with DMC1 }\end{array}$ & & (Siaud et al. 2004) \\
\hline AtSPO11-1 & Catalyses double-stranded DNA repair & SPO11 (yeast) & (Grelon et al. 2001) \\
\hline $\begin{array}{l}\text { MS5/TDM/ } \\
\text { POLLEN-LESS3 }\end{array}$ & $\begin{array}{l}\text { Homology to SC protein } \\
\text { and contains regulatory subunit } \\
\text { of cyclin-dependent kinase }\end{array}$ & SCP1 (rat) & (Glover et al. 1998) \\
\hline ASK1 & $\begin{array}{l}\text { Skp1-like. Possible role } \\
\text { in removing protein } \\
\text { from homologue complex }\end{array}$ & SPK1 & (Yang et al. 1999a) \\
\hline STUD/TES & Plant kinesin, role in male cytokinesis & NAK1, NAK2 (tobacco) & (Yang et al. 2003a) \\
\hline MMD1/DUET & $\begin{array}{l}\text { PHD-finger transcription factor } \\
\text { involved in male meiosis }\end{array}$ & & (Reddy et al. 2003, Yang et al. 2003c) \\
\hline$Q R T$ & Pollen remains in tetrad & & (Preuss et al. 1994) \\
\hline$A K V$ & Degeneration of megaspores & & (Yang \& Sundaresan 2000) \\
\hline$G F$ & $\begin{array}{l}\text { Defect in female mitotic divisions. } \\
\text { Possible roles in cell cycle machinery }\end{array}$ & & $\begin{array}{l}\text { (Drews et al. 1998, } \\
\text { Yang \& Sundaresan 2000) }\end{array}$ \\
\hline $\begin{array}{l}\text { FEM2 } \\
\text { FEM3 } \\
\text { GFA4 } \\
\text { GFA5 } \\
\text { CDC16 } \\
\text { PR1 }\end{array}$ & & & \\
\hline MS1 & $\begin{array}{l}\text { PHD-finger transcription } \\
\text { factor-microspore maturation }\end{array}$ & & (Wilson et al. 2001) \\
\hline AMS1 & bHLH MYC transcription regulator & & (Sorensen et al. 2003) \\
\hline SIDECAR & Pollen asymmetric division & & (Chen \& McCormick 1996) \\
\hline GEM1 & Asymmetric PMl & & (Park et al. 1998) \\
\hline GFA2 & $\begin{array}{l}\text { Aberrations in polar nuclei fusion, } \\
\text { migration and cellularisation }\end{array}$ & & (Yang \& Sundaresan 2000) \\
\hline $\begin{array}{l}\text { GFA3 } \\
\text { GFA7 }\end{array}$ & & & \\
\hline FEM4 & Embryo sac cell morphogenesis & & (Yang \& Sundaresan 2000) \\
\hline
\end{tabular}


which contains the haploid pollen and the ovule for the female which contains the embryo sac and is the progenitor of the seed (Fig. 1). The initiation process occurs in a similar manner for both male and female gametes with the differentiation of archesporial cells and initiation of meiosis.

Male gamete formation is initiated by periclinal divisions (parallel to the anther wall) in several adjacent hypodermal cells within the anther primordium, these develop into archespores, typically with four situated at the four corners of each anther primordium. The archesporial cells then divide mitotically to form the inner primary sporogenous cells, which later go to form pollen mother cells (PMCs) and primary parietal cells (Scott et al. 2004). In Arabidopsis there are approximately 30 PMCs per anther. The primary parietal cells go through further mitotic divisions to form the anther wall comprising of the endothecium, middle cell layer and tapetum (Fig. 1B). The tapetum surrounds the sporogenous cells and serves to nourish the developing microspores during the process of PMC meiosis and microspore maturation. Callose $(\beta 1,3$ glucan) forms around the PMCs and later between the meiotic products, normal plasmodesmata links between the microspores are severed, however as meiosis proceeds the plasmodesmata expand to form 'cytomictic channels' of up to $0.5 \mu \mathrm{m}$ through which some cytoplasmic exchange is likely to occur (Heslop-Harrison 1966). After meiosis, the callose is broken down by the release of a $\beta 1,3$ glucanase (callase) by the tapetum. The timing of this is crucial for pollen viability and this has been used as an approach to engineer male sterility artificially (Worrall et al. 1992, Rhee \& Somerville 1998); however, the analysis of such lines suggests that the callose wall is not required for male meiosis (Scott et al. 2004).
The microspores then go through a process of wall deposition, co-ordinated by the tapetum but also in part by the microspores/immature pollen grains (Piffanelli et al. 1998, Scott et al. 2004). Two further mitotic divisions occur to produce functional male gametes. These can occur during the late stages of pollen development as seen in species that produce tricellular pollen, e.g. Arabidopsis. Alternatively, the first mitotic division (pollen mitosis I; PMI) may occur in the pollen grain so that, when released, the mature pollen is bicellular, e.g. tobacco, and the further mitotic division (pollen mitosis II; PMII) occurs during pollen tube development. The PMI division is asymmetric and establishes polarity and determinacy within the pollen grain (Eady et al. 1995). The two cells formed have very distinct fates, the larger vegetative cell accumulates a dense cytoplasm containing lipids, proteins and carbohydrates (McCormick 2004). This does not divide further, but provides storage compounds for the active period of growth associated with the production of a pollen tube. The other generative cell is smaller with highly condensed chromatin, subsequently it goes through PMII to produce two sperm cells. Double fertilisation is characteristically seen in plants (Faure 2001), with one sperm cell fusing with the egg cell to form an embryo, whilst the other fuses with the diploid central cell to form the endosperm. The endosperm is a triploid tissue that serves to nourish the developing embryo prior to the commencement of functional photosynthesis by the developing seedling.

Female gamete formation occurs within the ovule (Schneitz et al. 1998, Yang \& Sundaresan 2000, Skinner et al. 2004). Different types of female gametophyte development have been described; however, $>70 \%$ of flowering plants exhibit the Polygonium type pattern of

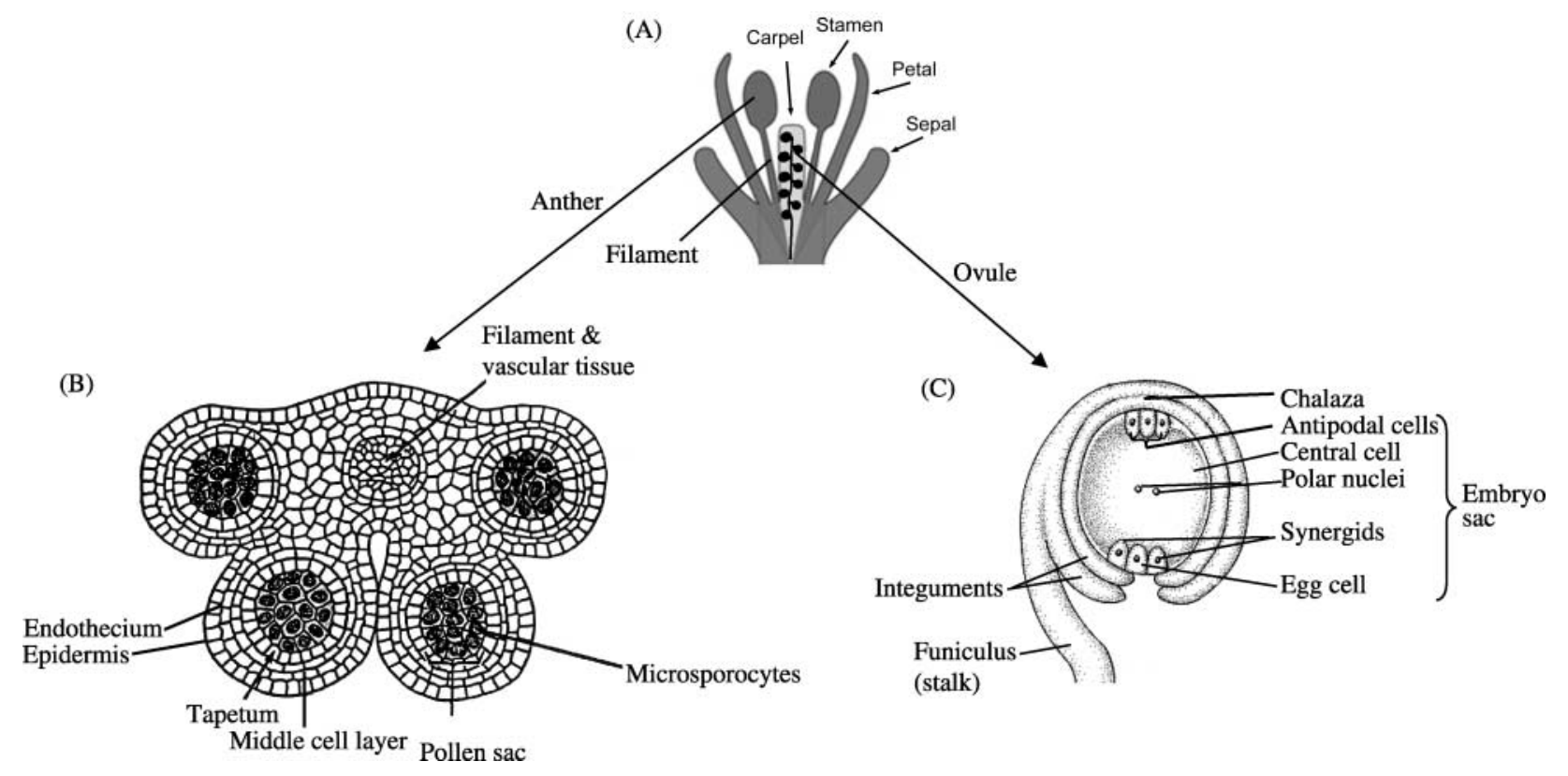

Figure 1 The Arabidopsis gametophyte; (A) floral structure, (B) anther and (C) ovule. 
development resulting in an eight nucleate embryo sac (Drews \& Yadegari 2002, Yadegari \& Drews 2004). A typical Arabidopsis gynoecium comprises of approximately 50 ovules. Each ovule comprises of a nucellus that encloses the embryo sac, which is encased within two integuments that are the progenitors of the seed coat. The integuments grow asymmetrically leading to the curvature typically observed in mature ovules (Schneitz et al. 1998, Skinner et al. 2004); the funiculus or stalk connects the ovule to the placenta (Fig. 1C).

The nucellus contains the spore-bearing tissue (megaspore mother cell (MMC)). The MMC goes through meiosis to form four haploid megaspores; however, between one and three of these degenerate via programmed cell death, usually leaving only one functional megaspore at the chalazal end. This then goes through four successive mitotic divisions to form the eight-nucleate embryo sac (Schneitz et al. 1998, Skinner et al. 2004). Two of these nuclei then fuse to form the central cell, which is diploid and is later fertilised by one of the sperm cells to form the triploid endosperm. A typical embryo sac therefore comprises of seven cells with eight nuclei (Fig. 1C). The nucellus is usually encapsulated by two integuments, except for a small cleft at the base, termed the micropyle, through which the pollen tube grows to allow double fertilisation by the two sperm cells. The nucellar tissue goes through degeneration during embryo sac development. The integuments which ultimately form the seed coat are also thought to have a role in the regulation of nucellar degeneration and sporophyte development (Schneitz et al. 1998, Skinner et al. 2004).

\section{Regulation of sporocyte development}

Meiosis in higher plants proceeds in a similar fashion to other higher eukaryotes, with many of the processes such as pairing and recombination conserved; however, little is known about the critical signals that switch cellular development from a diploid, sporophytic generation to a haploid, generative generation. This switch occurs late in the development of plant cells, and can be induced in previously undifferentiated tissue and divides the sporophytic and gametophytic generations.

A number of genes that function in determining the specification of the male or female germline have been identified in Arabidopsis (Table 1 and Fig. 2) and a detailed analysis of the developmental process of meiosis in wildtype plants and meiotic mutants has been conducted (Ross et al. 1996, 1997, Bhatt et al. 2001). The SPOROCYTELESS (SPL)/NOZZLE (NZZ) gene has homology to MADS box transcriptional factors and is required for the initiation of sporogenesis in both male and female organs (Schiefthaler et al. 1999, Yang et al. 1999b). In the spl/nzz mutant, archesporial initiation occurs normally; however, subsequent differentiation of both the male and female sporocytes is blocked. Anther wall development also fails to occur, but integument development is normal although nucellus development is delayed (Yang et al. 1999b). This suggests that the interactions of SPL/NZZ with the surrounding cells determine the outcome within the anther and ovule. Yang et al. (1999b) propose that the microsporocytes promote, via cell-to-cell communication or via passage of a signal, the differentiation and growth of the anther parietal layers and thus wall development. In the sterile apetela (sap) mutant, megasporocytes fail to complete meiosis and floral number and organ number are also affected (Byzova et al. 1999). However, since megasporocyte formation occurs in sap mutants, it is therefore proposed that $S A P$ may act downstream of $S P L / N Z Z$.

The MULTIPLE ARCHESPORIAL CELLS1 (MAC1) gene from maize appears to function at an earlier stage to SPL/NZZ since it alters the specification of archesporial cells. In the mac1 mutant, multiple archesporial cells form in the ovule (Sheridan et al. 1996); however, in the anther archesporial specification is unaffected but meiotic arrest is seen. This implies that $S P L / N Z Z$ may act upstream of $M A C 1$ in the anthers (Yang et al. 1999b). A similar phenotype of altered numbers of archesporial cells is seen in the Arabidopsis mutants extra sporogenous cells (exs)/excess microsporocytes 1 (ems1) and tapetal determinant 1 (tpd1) and the EXS/EMS1 rice orthologue MULTIPLE SPOROCYTE1 (MSP1) (Nonomura et al. 2003). EXS/EMS1 appears to regulate the number of cells that divide in the L2 layer of the anther (goes to form archesporial cells) and therefore the number of sporogenous cell initials. In the exs/ems1 mutant, additional meiocytes are formed, but the tapetal and middle cell layers are also missing; this is also seen in the gus negative1 (gne1) mutant (Sorensen et al. 2002). The EXS/EMS1 gene encodes for a putative serine/threonine LRR (leucine rich repeat) receptor kinase (Canales et al. 2002, Zhao et al. 2002) and is thought to act by complexing with different partners in the different tissues and therefore to restrict growth within the L2 layer of the anther or enhance growth in the embryo (Canales et al. 2002). A similar phenotype of the tapetal cells being replaced by sporogenous cells is observed in the mutant tpd1. TPD1 is expressed predominantly within the microsporocytes and may reflect interactions between the developing sporocytes and tapetal cells, with the formation of sporocytes as a default pathway in the absence of TPD1 (Yang et al. 2003b). TPD1 encodes for a small protein of 176 amino acids and is thought to act in COordination with EXS/EMS1 (Yang et al. 2003b). The formation of sporogenous cells in the absence of the tapetum in tpd1 and exs/ems1 mutants implies that sporocytes can form, and the process of meiosis can be initiated in the absence of the tapetal cell layer; however, both mutants are male sterile with degeneration of the microsporocytes occurring during meiosis II, suggesting that the development of viable pollen requires a functional tapetum.

The Arabidopsis loci SWITCH1/DYAD and the maize AMEIOTIC1 have been implicated in the switch from sporophytic to gametophytic development. In the ameiotic mutant, both mega and microsporocytes are formed, but 


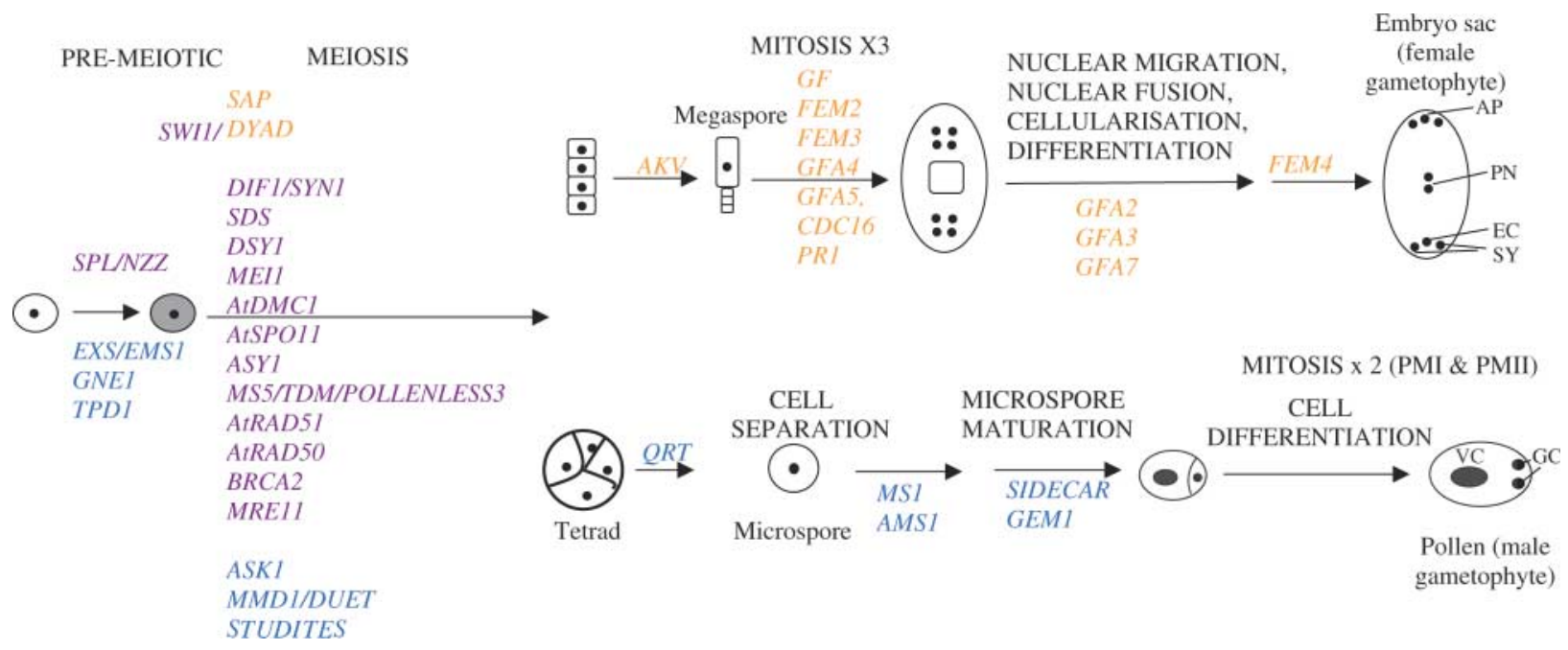

Figure 2 Schematic representation of the events leading to gamete formation in Arabidopsis. The genes that have been characterised as playing key roles have been positioned adjacent to the developmental stage in which they are involved. Genes that are involved in female gamete development are shown in yellow, male gametogenesis in blue, and those which impact on both male and female gamete formation are in purple. AP, antipodal cells; PN, polar nuclei; EC, egg cell; SY, synergids; VC, vegetative cell; GC, generative cells.

meiosis does not proceed, with ameiotic1 meiocytes carrying out a form of mitotic-like division rather than meiosis after which they degenerate (Golubovskaya et al. 1993, 1997). In the ovules of swi1 mutant, archesporial cells undergo a further mitotic division before entering meiosis (Siddiqi et al. 2000).

Many of the genes that have been identified by mutagenesis as having a clear phenotype associated with meiosis, e.g. SWI1, SYN1, ASY1, are also expressed within the vegetative tissues. However, no mitotic phenotype has been seen with these genes, implying that they may be non-essential for mitosis, that there may be functional redundancy or that some form of post-translational regulation may regulate the developmental role of these proteins (Mercier et al. 2003).

\section{Sporophytic and gametophytic interactions}

It is evident that meiosis and the subsequent development of the gametes is regulated in part by the developing gametophytes, but also by the surrounding sporophytic tissue. This is true for both male and female gametes, with the tapetal tissues playing a major role in the development of pollen and the nucellus for egg cells.

The tapetum is a transient, metabolically active sporophytic cell layer, which encloses the sporogenous tissue within the anther locule (Chapman 1987). It plays a critical role in the nutrition of microspores, in the regulation of sporogenesis and in pollen wall development. Tapetal tissue is highly metabolically active and undergoes endoreplication to form bi- or multinucleate cells, with a proliferation of ribosomes (Weiss \& Maluszynska 2001). Polyploidisation of the tapetum is thought to occur to increase the potential for synthesis without cell division. The process of microspogenesis is extremely sensitive to mitochondrial mutations, as observed in cytoplasmic male sterile lines (Schnable \& Wise 1998) which typically show tapetal aberrations but have no specific vegetative phenotypes, suggesting that microsporogenesis and tapetal development is an extremely energy-demanding process. The tapetum plays a major secretory role in sporogenesis, in direct analogy to nurse cells in mammalian systems. It plays a key role in the secretion of pollen wall materials, primarily sporopollenin, which is composed of mixed polymers of fatty acid and phenylpropanoid derivatives and provides a critical function in pollen dispersal and pollen-stigma interactions (Piffanelli et al. 1998, Aouali et al. 2001). The tapetum is also critical in the secretion of callase ( $\beta 1,3$ glucanase) to regulate breakdown of the callose ( $\beta 1,3$-linked glucan) wall surrounding the tetrads. During microspore maturation, the tapetum undergoes a process of highly regulated programmed cell death resulting in the release of cell wall and lipid compounds and its final disintegration prior to anthesis.

A similar pattern of nucellus degradation is observed during the later stages of female embryo sac development; however, normal breakdown does not occur in the sap mutant in which megasporogenesis is arrested (Byzova et al. 1999). It is therefore speculated that a functional megaspore may be needed for nucellus degradation and that signals from the integument are required for regulating the progression of meiosis in the female gametes (Yang \& Sundaresan 2000).

\section{Meiotic development}

Meiosis is a critical, highly conserved stage occurring during the sexual reproduction of all eukaryotes. A single round of DNA replication is combined with two successive divisions to form four haploid products that allow the 
process of reassortment and segregation of genetic information. The first separation involves the segregation of homologous chromosomes that have previously undergone pairing to form bivalents, synapsis and recombination. The second division then involves the separation of sister chromatids of each chromosome resulting in four haploid gametes. Meiosis appears to be highly regulated and to proceed in a synchronous manner. However, as seen with many angiosperms there is a high degree of asynchrony between male and female meiosis and, in Arabidopsis, male meiosis is completed before female meiosis reaches prophase I (Caryl et al. 2003).

Large numbers of genes with established roles in meiosis and mitosis have been identified in yeast and humans and although sequence analysis has been used to identify homologues and aid functional classification of genes it has had mixed success. For instance, although the synaptonemal complex (SC) exhibits high levels of functional similarity in plants and animals, the search for functional homologues of SC proteins has not been very successful. However, to some extent this may be expected, since low levels of homology are seen between yeast and mammalian systems. For example, the yeast ZAPI1 and rat $S C P 1$ genes both encode for proteins associated with the synaptonemal complex; however, the only regions of similarity are within the coiled-coil regions (Heyting 1996). A more successful approach to identify genes with a critical role in plant meiosis has been the analysis of sterile or reduced fertility mutants (Caryl et al. 2003). This has identified a number of genes that act in either male or female meiosis, or both, and their roles have subsequently been compared with those in yeast and higher eukaryotes.

\section{Chromosome pairing and synapsis}

The process of chromosome condensation and pairing occurs during five distinct, conserved stages during meiosis 1 (Ross et al. 1996, 1997). During leptotene the chromosomes condense, appearing as thin thread-like structures and homologous pairing is initiated. Pairing continues during zygotene until full synapsis is seen by pachytene. At this point, the homologues have fully paired and appear as thick structures and the SC forms. During diplotene, desynapsis begins to occur with the homologues remaining attached at the points of chiasmata. By diakinesis, the chromosomes appear as condensed bivalents and the homologues are critically attached as they enter anaphase I. Meiotic recombination occurs during late leptotene/zygotene.

Cohesins are a group of evolutionary conserved proteins that have been implicated in the close association seen between replicated sister chromatids during prophase I, and have a potential role in recombination and doublestrand break repair (reviewed by Nasmyth 2001). In budding and fission yeast, two cohesins have been characterised. The RAD21 protein was first identified from Schizosaccharomyces pombe as essential in

Reproduction (2004) 128 483-492 double-stranded DNA repair during mitotic growth. $R A D 21$ is a cell cycle-regulated phosphoprotein required for chromosome condensation and sister chromatid cohesion. A similar meiotically expressed gene, $R A D 8$, has also been identified in $S$. pombe. A small RAD21 family with cohesin activity has been identified in Arabidopsis. It is predicted that these may have defined roles associated with chromosome condensation during mitosis and meiosis (Bai et al. 1999). The DIF1/SYN1 gene has greatest sequence homology to RAD21; however, DIF1/SYN1 is meiotically active, exhibiting both male and female sterility, when mutated, due to a lack of chromosome condensation and pairing during leptoneme of meiosis I (Bai et al. 1999, Bhatt et al. 1999).

Mutation of the Arabidopsis SOLO DANCERS (SDS) gene results in a severe defect in homologue synapsis, recombination and bivalent formation during prophase I of meiosis in both male and female sporocytes, causing random distribution of the chromosomes and abnormal meiotic products (Azumi et al. 2002). In the C-terminal region, SDS contains a conserved cyclin-like domain which has most similarity to the B2 subtype of Arabidopsis $\mathrm{B}$ cyclins. However, the levels of similarity are similar to that seen between the Arabidopsis A, B and D types of cyclins; it is therefore speculated that SDS may represent a new type of cyclin (Azumi et al. 2002). It is proposed that homologue interactions require a novel meiosis-specific cyclin, suggesting that a cyclin dependent kinase may play a key role in controlling chromosomal events during meiotic prophase I. SDS appears to be meiosis specific and not expressed in vegetative tissue (Azumi et al. 2002).

Arabidopsis SWITCH (SWI1) is a novel protein that appears to colocalise with DNA and is needed to promote sister chromatid cohesion, axial element formation and recombination. In the swi1 mutant, 20 individual chromatids are observed at metaphase 1 rather than five bivalents. Condensation is, however, seen in the swi1 mutant implying that SWI1 is involved in initiation of cohesion rather than condensation; also, since the protein does not persist beyond meiosis I, it appears not to be involved in maintenance of cohesion (Mercier et al. 2003). SDS is proposed to be involved in the timing of chromosome separation by the phosphorylation of proteins involved in sister chromosome cohesion; it is therefore possible that SDS may regulate SWI1 activity (Azumi et al. 2002).

The Arabidopsis ASY1 gene is essential for both male and female homologous chromosome synapsis and has been linked to the SC; when mutated, the chromosomes align during diakinesis, but no bivalents or chiasmata are detected. A second ASY2 gene has also been identified in the Arabidopsis genome but the function of this is unknown. The ASY1 gene transcript is also detected in vegetative tissue but no vegetative phenotype is observed, expression in vegetative tissue is also seen with a number of other meiotic genes despite a lack of mitotic phenotype, e.g. syn1 (Bai et al. 1999). ASY1 is detected in PMCs during meiotic interphase as punctate foci that are 
distributed over the chromatin. As leptotene progresses it associates with the axial loops, but not the associated extended chromatin loops and then extends over the length of the chromatin, not including the telomeres (Armstrong et al. 2002). As the homologues desynapse the protein disappears. The ASY1 protein has homology to the $\mathrm{N}$-terminus of the yeast homeodomain protein 1 (HOP1) axial core-associated protein (Caryl et al. 2000). The region of homology contains a HORMA domain, found in proteins that associate with chromatin. Homology over the remainder of the protein is however low, therefore functional similarity between the proteins may not extend beyond the ability of both proteins to bind chromatin (Armstrong et al. 2002). HOP1 is seen to associate in a similar manner to ASY1 as a series of foci in leptotene, which in yeast is dependent upon another protein RED1, that is needed for axial element assembly (Smith \& Roeder 1997). Both ASY1 and RED1 have similar expression patterns and appear to work together albeit with defined roles. However, no sequence homology is seen between RED1 and ASY1, or to any other Arabidopsis proteins. ASY1 may therefore serve a similar role to the HOP1/RED1 proteins with a crucial function associated with the interface between the SC and axis-associated chromatin (Armstrong et al. 2002).

Homologues of a number of genes that are required for the catalytic steps of recombination in yeast and vertebrates have now been identified in Arabidopsis, including RAD51, DMC1, RAD50, SPO11, MRE11 (Klimyuk \& Jones 1997, Doutriaux et al. 1998, Couteau et al. 1999, Gallego et al. 2001, Gallego \& White 2001, Grelon et al. 2001, Puizina et al. 2004). The yeast DMC1 protein has been shown to be essential for the formation of bivalents and partitioning of chromosomes during meiosis I. Mutation of the Arabidopsis orthologue, AtDMC1, results in a reduction of fertility to $\sim 1.5 \%$ and a failure of chromosome partitioning although, significantly, complete meiotic arrest as seen in yeast (Couteau et al. 1999) does not occur. This suggests that a distinct mechanism of checkpoint activation or progression surveillance may exist in plants as compared with yeast (Bhatt et al. 1999).

The Mre11 protein complex, which is composed of Mre11, Rad50 and Xrs2 and which has been characterised in Saccharomyces cerevisiae and vertebrate systems, plays a central role in the initial stages of double-strand break (DSB) repair (Ray \& Langer 2002). This system of DSB repair appears to be conserved in plants, although differences exist, e.g. the loss of a functional Mre11 complex results in lethality in vertebrate systems whilst viability is maintained in plants (Daoudal-Cotterell et al. 2002, Puizina et al. 2004). In Arabidopsis, the MRE11 gene has been shown to be required for DSB repair, but not for the induction of Spo11-dependent meiotic DNA breaks (Puizina et al. 2004). Mutation of the Arabidopsis RAD50 gene has resulted in sterility and hypersensitivity to the DNAdamaging agent methylmethane sulphonate suggesting a conserved role for AtRAD50 in DSB repair in plant cells (Gallego et al. 2001).

In Saccharomyces cerevisiae, SPO11 catalyses DSBs that initiate recombination during meiosis and result in SC formation. Loss of DSB in yeast results in the loss of synapsis. SPO11 homologues have been identified in many other eukaryotes, e.g. C. elegans and Drosophila. In yeast and other eukaryotes, only one SPO11 homologue has been identified; however, in Arabidopsis three have been found. Thus the SPO11 role in initiating DSB and recombination appears to be conserved in higher plants, with AtSPO11-1 gene reducing DSBs and bivalent formation in prophase I in both male and female meiosis. Recombination is therefore initiated in Arabidopsis by the formation of DSBs; gametogenesis is, however, not completely prevented in the Atspo11 mutant, as seen in $S$. cerevisiae, although fertility is greatly reduced.

A conserved group of RAD51-like proteins have been identified in yeast through to vertebrates. These have a role in recombination and damage repair pathways and are homologous to the prokaryotic RECA protein. Paralogues of all six vertebrate Rad51-like genes have been identified in the Arabidopsis genome. Mutation of one of these, Atxrcc3 results in aberrant male and female gametogenesis. These plants are also hypersensitive to DNA-damage treatments, supporting the role of Rad51like proteins in recombination repair (Bleuyard \& White 2004). Yeast two-hybrid assays suggest that RAD51 and DMC1 associate with the BRCA2 protein and play a role in homologous recombination and meiotic progression (Siaud et al. 2004). This is supported by the failure of meiosis and aberrant recombination events in RNA interference silenced $B R C A 2$ lines.

In yeast and humans, SKP1 genes have been shown to regulate the mitotic cycle, but no role has yet been assigned to the meiotic cycle. In Arabidopsis, nine SKP1LIKE genes have been identified with roles in both the vegetative and generative cycles. The ASK1 gene when mutated results in male sterility and abnormally sized microspores due to a defect in homologue separation (Yang et al. 1999a). Homologous pairing occurs during metaphase I; however, uneven segregation occurs during anaphase I with some of the homologues remaining associated after metaphase. Spindle formation, as judged by immunofluorescence microscopy, appears normal. The yeast SPK1 gene is required for entry into the $S$ phase and for completion of the $M$ phase of mitosis. SPK1p has an essential role in the ubiquitin-ligase complex SCF which targets specific proteins for ubiquitination proteolysis. It is not known whether Spk1p has a role in meiosis in yeast or humans. Yang et al. (1999a) have proposed that SPKP1-LIKE1 (ASK1) may play a role in removing protein(s) that is needed for homologue association before anaphase I. They speculate that ubiquitin-mediated proteolysis may play a role in other instances of chromosomal separation. The other SPK1-LIKE genes may have specific roles associated with other developmental 
processes, e.g. vegetative growth, which has come about due to ancestral duplication and functional divergence.

The MS5/TDM/POLLENLESS3 gene when mutated result in 'polyads', which are tetrads with more than four pools of chromosomes after male meiosis due to an additional division after meiosis II (Ross et al. 1997). The MS5 protein has a low level of similarity to the rat synaptonemal complex protein 1 and has a regulatory subunit of cyclindependent kinase (Glover et al. 1998).

Separation of the microspores after meiosis fails to occur in the stud/tetraspore (std/tes) mutant due to a failure in male cytokinesis (Hulskamp et al. 1997, Spielman et al. 1997). This results in the formation of large tetraspores containing all four meiotic products that go through PMI and PMII forming multiple gametes in enlarged pollen grains, some of which are viable, and polyploidy embryos can be formed through fertilisation using std/tes pollen. In the std/tes mutant, radial arrays of microtubule associated with male meiotic cytokinesis fail to form. The TES protein has homology to a small number of plant kinesins and it is speculated that it plays a role as a microtubule-associated motor, possibly as homo- or heterodimers as seen in other kinesins (Yang et al. 2003a). A number of kinesin-like proteins have been identified in eukaryotes and are thought to be involved in transport along microtubules and possibly microtubule polymerisation and depolymerisation. TES is one of 61 kinesins identified in the Arabidopsis genome, it is expressed both in vegetative and reproductive tissues; however, no phenotype has been associated with vegetative development. It is thought that a degree of redundancy may exist between the different kinesins.

\section{Transcriptional regulation of gametophyte development}

A number of transcription factors have been identified during gamete formation in plants that have homology to transcription regulators of yeast and mammals. The SPL/NZZ gene has limited homology to the MADS box family of transcription factors. It has been linked to early germline specification and for establishment of patterning within the ovule (Schiefthaler et al. 1999, Yang et al. $1999 b$ ) and is thought to be involved in the regulation of gene expression associated with the switch towards gametophytic development.

The MALE STERILITY1 gene has homology to the plant homeo domain (PHD)-finger group of transcriptional regulators and acts during callose wall breakdown and as the microspores are released. It is thought that it may regulate tapetal gene expression and thus pollen development within the anther (Wilson et al. 2001). Another PHD-finger transcription factor has been identified in Arabidopsis, MALE MEIOCYTE DEATH1 (MMD1). Mutants in MMD1 show defects in male meiotic development only and appear to trigger cell death in the meiocytes (Yang et al. 2003c).
Mutation of the ABORTED MICROSPORE1 gene results in empty anthers that do not contain any pollen due to premature degeneration of the tapetum and microspores (Sorensen et al. 2003). The AMS1 gene has homology to the basic helix-loop-helix (bHLH) group of the MYC subfamily of bHLH genes and is thought to regulate post-meiotic gene expression in the anther (Sorensen et al. 2003).

\section{Synteny between animals and plants}

A number of processes associated with gamete development are conserved between plants, yeasts and animals and much has been learnt by the comparative analysis between species (Walbot \& Evans 2003). A summary of the developmental staging of these genes is shown in Fig. 2, and their functional roles and orthologs are given in Table 1. The analysis of yeast has led the way towards the establishment of genes that are critically associated with meiosis. However, plants can now be seen to have a significant role to play in the elucidation of the processes of gamete development. The large chromosomes that are typical of many plant species make cytological analysis technically less challenging, the ability to dissect gametophytic from sporophytic development and the ability to identify and characterise mutations in key genes associated with gamete formation mean that the study of plants gametes may provide useful tools for reproductive development studies in animals.

\section{Acknowledgements}

We would like to thank Gema Vizcay Barrena and Katie Clarke. Our work on male gamete development has been supported by the BBSRC.

\section{References}

Aouali N, Laporte P \& Clement C 2001 Pectin secretion and distribution in the anther during pollen development in Lilium. Planta 213 71-79.

Armstrong SJ, Caryl AP, Jones GH \& Franklin CH 2002 Asy1, a protein required for meiotic chromosome synapsis, localizes to axisassociated chromatin in Arabidopsis and Brassica. Journal of Cell Science 115 3645-3655.

Azumi Y, Liu D, Zhao D, Li W, Wang G, Hu Y \& Ma H 2002 Homo$\log$ interaction during meiotic prophase $\mathrm{I}$ in Arabidopsis requires the SOLO DANCERS gene encoding a novel cyclin-like protein. EMBO Journal $213081-3095$.

Bai XF, Peirson BN, Dong FG, Xue C \& Makaroff CA 1999 Isolation and characterization of SYN1, a RAD21-like gene essential for meiosis in Arabidopsis. The Plant Cell 11 417-430.

Bhatt AM, Lister C, Page T, Fransz P, Findlay K, Jones GH, Dickinson HG \& Dean C 1999 The DIF1 gene of Arabidopsis is required for meiotic chromosome segregation and belongs to the REC8/RAD21 cohesin gene family. The Plant Journal 19 463-472.

Bhatt AM, Canales C \& Dickinson HG 2001 Plant meiosis: the means to $1 \mathrm{~N}$. Trends in Plant Science 6 114-121.

Bleuyard JY \& White CI 2004 The Arabidopsis homologue of Xrcc3 plays an essential role in meiosis. EMBO Journal 23 439-449.

Byzova MV, Franken J, Aarts MG, de Almeida-Engler J, Engler G, Mariani C, Van Lookeren Campagne MM \& Angenent GC 1999 
Arabidopsis STERILE APETALA, a multifunctional gene regulating inflorescence, flower, and ovule development. Genes and Development 13 1002-1014.

Canales C, Bhatt AM, Scott R \& Dickinson H 2002 EXS, a putative LRR receptor kinase, regulates male germline cell number and tapetal identity and promotes seed development in Arabidopsis. Current Biology 12 1718-1727.

Caryl AP, Armstrong SJ, Jones GH \& Franklin FC 2000 A homologue of the yeast HOP1 gene is inactivated in the Arabidopsis meiotic mutant asy1. Chromosoma $10962-71$.

Caryl AP, Jones GH \& Franklin FCH 2003 Dissecting plant meiosis using Arabidopsis thaliana mutants. Journal of Experimental Botany $5425-38$.

Chapman GP 1987 The tapetum. International Review of Cytology $107111-125$

Chen YC \& McCormick S 1996 Sidecar pollen, an Arabidopsis thaliana male gametophytic mutant with aberrant cell divisions during pollen development. Development 122 3243-3253.

Couteau F, Belzile F, Horlow C, Grandjean O, Vezon D \& Doutriaux MP 1999 Random chromosome segregation without meiotic arrest in both male and female meiocytes of a dmc1 mutant of Arabidopsis. The Plant Cell 11 1623-1634.

Daoudal-Cotterell S, Gallego ME \& White CI 2002 The plant Rad50Mre11 protein complex. FEBS Letters 516 164-166.

Doutriaux MP, Couteau F, Bergounioux C \& White C 1998 Isolation and characterisation of the RAD51 and DMC1 homologs from Arabidopsis thaliana. Molecular and General Genetics 257 283-291.

Drews GN \& Yadegari R 2002 Development and function of the angiosperm female gametophyte. Annual Review of Genetics 36 99-124.

Drews GN, Lee D \& Christensen CA 1998 Genetic analysis of female gametophyte development and function. The Plant Cell 10 5-17.

Eady C, Lindsey K \& Twell D 1995 The significance of microspore division and division symmetry for vegetative cell-specific transcription and generative cell differentiation. The Plant Cell 7 65-74.

Faure JE 2001 Double fertilization in flowering plants: discovery, study methods and mechanisms. Comptes Rendus de l'Academie des Sciences Serie III 324 551-558.

Gallego ME \& White CI 2001 RAD50 function is essential for telomere maintenance in Arabidopsis. PNAS 98 1711-1716.

Gallego ME, Jeanneau M, Granier F, Bouchez D, Bechtold N \& White CI 2001 Disruption of the Arabidopsis RAD50 gene leads to plant sterility and MMS sensitivity. The Plant Journal 25 31-41.

Glover J, Grelon M, Craig S, Chaudhury A \& Dennis E 1998 Cloning and characterization of MS5 from Arabidopsis: a gene critical in male meiosis. The Plant Journal 15 345-356.

Golubovskaya I, Grebennikova ZK, Avalkina NA \& Sheridan WF 1993 The role of the ameiotic1 gene in the initiation of meiosis and in subsequent meiotic events in maize. Genetics 135 1151-1166.

Golubovskaya I, Avalkina N \& Sheridan WF 1997 New insights into the role of the maize ameiotic1 locus. Genetics 147 1339-1350.

Grelon M, Vezon D, Gendrot G \& Pelletier G 2001 AtSPO11-1 is necessary for efficient meiotic recombination in plants. $E M B O$ Journal 20 589-600.

He CP \& Mascarenhas JP 1998 MEI1, an Arabidopsis gene required for male meiosis: isolation and characterization. Sexual Plant Reproduction 11 199-207.

Heslop-Harrison J 1966 Cytoplasmic connections between angiosperm meiocytes. Annals of Botany 30 221-230.

Heyting C 1996 Synaptonemal complexes: structure and function. Current Opinion in Cell Biology 8 389-396.

Hulskamp M, Parekh NS, Grini P, Schneitz K, Zimmermann I, Lolle SJ \& Pruitt RE 1997 The STUD gene is required for male-specific cytokinesis after telophase II of meiosis in Arabidopsis thaliana. Developmental Biology 187 114-124.

Klimyuk VI \& Jones JD 1997 AtDMC1, the Arabidopsis homologue of the yeast DMC1 gene: characterization, transposon-induced allelic variation and meiosis-associated expression. The Plant Journal 11 1-14.
McCormick S 2004 Control of male gametophyte development. The Plant Cell 16 (Suppl 1) S142-S153.

Meinke DW, Cherry JM, Dean C, Rounsley SD \& Koornneef M 1998 Arabidopsis thaliana: a model plant for genome analysis. Science 282662 and 679-682.

Mercier R, Armstrong SJ, Horlow C, Jackson NP, Makaroff CA Vezon D, Pelletier G, Jones GH \& Franklin FC 2003 The meiotic protein SWI1 is required for axial element formation and recombination initiation in Arabidopsis. Development $\mathbf{1 3 0}$ 3309-3318.

Nasmyth K 2001 Disseminating the genome: joining, resolving and separating sister chromatids during mitosis and meiosis. Annual Review of Genetics 35 673-745.

Nonomura K, Miyoshi K, Eiguchi M, Suzuki T, Miyao A, Hirochika H \& Kurata N 2003 The MSP1 gene is necessary to restrict the number of cells entering into male and female sporogenesis and to initiate anther wall formation in rice. The Plant Cell 15 1728-1739.

Park SK, Howden R \& Twell D 1998 The Arabidopsis thaliana gametophytic mutation gemini pollen1 disrupts microspore polarity, division asymmetry and pollen cell fate. Development $\mathbf{1 2 5}$ 3789-3799.

Piffanelli P, Ross JHE \& Murphy DJ 1998 Biogenesis and function of the lipidic structures of pollen grains. Sexual Plant Reproduction $1165-80$.

Preuss D, Rhee S \& Davis R 1994 Tetrad analysis possible in Arabidopsis with mutation of the QUARTET (QRT) genes. Science 264 1458-1460.

Puizina J, Siroky J, Mokros P, Schweizer D \& Riha K 2004 Mre11 deficiency in Arabidopsis is associated with chromosomal instability in somatic cells and Spo11-dependent genome fragmentation during meiosis. The Plant Cell 16 1968-1978.

Ray A \& Langer M 2002 Homologous recombination: ends as the means. Trends in Plant Science 7 435-440.

Reddy TV, Kaur J, Agashe B, Sundaresan V \& Siddiqi I 2003 The DUET gene is necessary for chromosome organization and progression during male meiosis in Arabidopsis and encodes a PHD finger protein. Development 130 5975-5987.

Rhee SY \& Somerville CR 1998 Tetrad pollen formation in quartet mutants of Arabidopsis thaliana is associated with persistence of pectic polysaccharides of the pollen mother cell wall. The Plant Journal 15 79-88.

Ross KJ, Fransz P \& Jones GH 1996 A light microscopic atlas of meiosis in Arabidopsis thaliana. Chromosome Research 4 507-516.

Ross KJ, Fransz P, Armstrong SJ, Vizir I, Mulligan B, Franklin FCH \& Jones GH 1997 Cytological characterization of four meiotic mutants of Arabidopsis isolated from T-DNA-transformed lines. Chromosome Research 5 551-559.

Schiefthaler U, Balasubramanian S, Sieber P, Chevalier D, Wisman E \& Schneitz K 1999 Molecular analysis of NOZZLE, a gene involved in pattern formation and early sporogenesis during sex organ development in Arabidopsis thaliana. PNAS 96 11664-11669.

Schnable PS \& Wise RP 1998 The molecular basis of cytoplasmic male sterility and fertility restoration. Trends in Plant Science 3 175-180.

Schneitz K, Balasubramanian S \& Schiefthaler U 1998 Organogenesis in plants: the molecular and genetic control of ovule development. Trends in Plant Science 3 468-472.

Scott RJ, Spielman M \& Dickinson HG 2004 Stamen structure and function. The Plant Cell 16 (Suppl 1) S46-S60.

Sheridan WF, Avalkina NA, Shamrov II, Batygina TB \& Golubovskaya IN 1996 The mac1 gene: controlling the commitment to the meiotic pathway in maize. Genetics 142 1009-1020.

Siaud N, Dray E, Gy I, Gerard E, Takvorian N \& Doutriaux MP 2004 Brca2 is involved in meiosis in Arabidopsis thaliana as suggested by its interaction with Dmc1. EMBO Journal 23 1392-1401. 
Siddiqi I, Ganesh G, Grossniklaus U \& Subbiah V 2000 The dyad gene is required for progression through female meiosis in Arabidopsis. Development 127 197-207.

Skinner DJ, Hill TA \& Gasser CS 2004 Regulation of ovule development. The Plant Cell 16 (Suppl 1) S32-S45.

Smith AV \& Roeder GS 1997 The yeast Red1 protein localizes to the cores of meiotic chromosomes. Journal of Cell Biology 136 957-967.

Sorensen A, Guerineau F, Canales-Holzeis C, Dickinson HG \& Scott RJ 2002 A novel extinction screen in Arabidopsis thaliana identifies mutant plants defective in early microsporangial development. The Plant Journal 29 581-594.

Sorensen AM, Krober S, Unte US, Huijser P, Dekker K \& Saedler H 2003 The Arabidopsis ABORTED MICROSPORES (AMS) gene encodes a MYC class transcription factor. The Plant Journal 33 413-423.

Spielman M, Preuss D, Li FL, Browne WE, Scott RJ \& Dickinson HG 1997 TETRASPORE is required for male meiotic cytokinesis in Arabidopsis thaliana. Development 124 2645-2657.

Walbot V \& Evans MMS 2003 Unique features of the plant life cycle and their consequences. Nature Genetics 4 369-379.

Weiss H \& Maluszynska J 2001 Molecular cytogenetic analysis of polyploidization in the anther tapetum of diploid and autotetraploid Arabidopsis thaliana plants. Annals of Botany 87 729-735.

Wilson ZA, Morroll SM, Dawson J, Swarup R \& Tighe PJ 2001 The Arabidopsis MALE STERILITY1(MS1) gene is a transcriptional regulator of male gametogenesis, with homology to the PHD-finger family of transcription factors. The Plant Journal 28 27-39.

Worrall D, Hird DL, Hodge R, Paul W, Draper J \& Scott R 1992 Premature dissolution of the microsporocyte callose wall causes male sterility in transgenic tobacco. The Plant Cell 4 759-771.
Wylie C 1999 Germ cells. Cell 96 165-174.

Yadegari R \& Drews GN 2004 Female gametophyte development. The Plant Cell 16 (Suppl 1) S133-S141.

Yang CY, Spielman M, Coles JP, Li Y, Ghelani S, Bourdon V, Brown RC, Lemmon BE, Scott RJ \& Dickinson HG 2003a TETRASPORE encodes a kinesin required for male meiotic cytokinesis in Arabidopsis. The Plant Journal 34 229-240.

Yang M, Hu Y, Lodhi M, McCombie WR \& Ma H 1999a The Arabidopsis SKP1-LIKE1 gene is essential for male meiosis and may control homologue separation. PNAS 96 11416-11421.

Yang SL, Xie LF, Mao HZ, Puah CS, Yang WC, Jiang L, Sundaresan V \& Ye D 2003b TAPETUM DETERMINANT1 is required for cell specialization in the Arabidopsis anther. The Plant Cell $\mathbf{1 5}$ $2792-2804$.

Yang WC \& Sundaresan V 2000 Genetics of gametophyte biogenesis in Arabidopsis. Current Opinion in Plant Biology 3 53-57.

Yang WC, Ye D, Xu J \& Sundaresan V 1999b The SPOROCYTELESS gene of Arabidopsis is required for initiation of sporogenesis and encodes a novel nuclear protein. Genes and Development 13 $2108-2117$.

Yang X, Makaroff CA \& Ma H 2003C The Arabidopsis MALE MEIOCYTE DEATH1 gene encodes a PHD-finger protein that is required for male meiosis. The Plant Cell 15 1281-1295.

Zhao DZ, Wang GF, Speal B \& Ma H 2002 The excess microsporocytes1 gene encodes a putative leucine-rich repeat receptor protein kinase that controls somatic and reproductive cell fates in the Arabidopsis anther. Genes and Development 16 2021-2031.

Zhao GQ \& Garbers DL 2002 Male germ cell specification and differentiation. Developmental Cell 2 537-547. 